\title{
Skills training in minimally invasive surgery in Dutch obstetrics and gynecology residency curriculum
}

\author{
Ellen Hiemstra • Wendela Kolkman • \\ Frank Willem Jansen
}

Received: 15 February 2008 / Accepted: 15 April 2008/Published online: 29 May 2008

(C) The Author(s) 2008

\begin{abstract}
The complexity of acquiring minimally invasive surgical (MIS) skills, combined with smaller case volumes for residents have pushed the development of skills training facilities on simulators outside the operating room (OR). Medico-legal and financial constraints have stimulated this development even more. However, the implementation of simulator training into a residency curriculum is shown to be troublesome. MIS skills training is organized in a uniform and easily applicable way in the Dutch obstetrics and gynecology residency curriculum. Every resident is obliged to attend the same basic surgical skills course, named Cobra-alpha course, intentionally during postgraduate year (PGY) 1 or 2. Furthermore, surgical skills are trained, evaluated and expanded on simulators in teaching hospitals. Additional to the Cobra-alpha course, residents may attend advanced training courses and congresses focusing on laparoscopy and hysteroscopy. This organization guarantees a uniform introduction to MIS skills training for every resident. However, preconditions for continuous training and evaluation after this introduction have to be optimized.
\end{abstract}

Keywords Surgical skills · Training · Simulation · Implementation $\cdot$ Residency curriculum

E. Hiemstra • W. Kolkman • F. W. Jansen $(\bowtie)$

Department of Gynecology,

Leiden University Medical Centre (LUMC),

P.O. Box 9600, 2300 RC,

Leiden, The Netherlands

e-mail: F.W.Jansen@lumc.nl

\section{Introduction}

Minimally invasive surgery (MIS) has evolved into a major surgical approach to treat a variety of gynecological disorders. This approach has considerable benefits for patients, such as a reduced morbidity, a shorter hospitalization, better cosmetic results, and an earlier return to normal activity [1].

However, acquiring MIS skills is more challenging than acquiring the skills necessary to perform conventional open surgical procedures. MIS poses specific demands on the surgeon. During MIS, the three-dimensional operating field has to be interpreted from a two-dimensional monitor display in which depth perception is altered. In addition, a surgeon has to manipulate long surgical instruments with diminished tactile feedback and fewer degrees of freedom, while adapting to the fulcrum effect $[2,3]$.

Apart from the complexity of acquiring MIS skills, a residency curriculum has to deal with smaller case volumes in the operating room (OR). This is due to a decrease in resident working hours and a declining trend in major gynecological surgical procedures in general $[4,5]$. The smaller case volumes, combined with issues such as quality control, patient safety, efficiency and cost-effectiveness have led to an increasing interest in simulator training facilities outside the OR $[3,6]$. Simulator training aims at progression along the learning curve by repetitive training of surgical skills with a lack a potential burden to patients in a pressure free environment. [3]

With regard to MIS training the implementation into residency programs is shown to be troublesome [7-9]. Even though basic laparoscopic procedures have well been incorporated in residency, more advanced procedures are not $[5,10]$. Lack of adequate training during residency influences the subsequent use of a specific technique and 
ultimately may restrict the implementation of MIS in daily practice after completion of residency training [11, 12].

In this report, we present the organization of MIS skills training in the Dutch obstetrics and gynecology residency curriculum which has continuously been evaluated and improved over the past 15 years.

\section{Surgical skills in the Dutch residency curriculum}

The obstetrics and gynecology residency program lasts 6 years in the Netherlands. A basic surgical skill course, named Cobra-alpha course, was incorporated in the curriculum in 1992. It has been evaluated and improved ever since. In 1997, this course was made compulsory for every resident. Attendance to this course is mandatory for obstetrics and gynecology residents during postgraduate year (PGY) 1 or 2 . One third of this two-day course is spent on theory, while the complementary two thirds are spent on hands-on training. The first day focuses on basic technical skills, like instrument handling and knot tying, for conventional surgery, while the second day concerns the basic skills required for MIS which is subdivided into laparoscopy and hysteroscopy. Two handbooks, focusing on the basics of surgery and laparoscopy, are used for study purposes and have been written for this course [13, 14].

The goal of the hands-on training in MIS during the Cobra-alpha course is to provide an introduction to simulator training for laparoscopic and hysteroscopic skills. Additionally, residents need to expand the acquired skills on simulators and have these skills evaluated by a mentor or MIS expert in their own clinic. Necessarily, time for training and evaluation has to be scheduled into the busy clinical practice of the residency program.

A range of simulators is available for the hands-on training. Inanimate box trainers are used to practice basic laparoscopic skills like hand-eye coordination, adaptation to the lack of depth perception and camera holding. The construct validity is established for five of the available exercises in the box trainers [15]. These five exercises are placing a pipe cleaner through four small circles, stretching a rubber band around 16 nails, placing 13 beads in a letter ' $\mathrm{B}$ ', cutting a marked circle from a rubber glove and intracorporeal knot tying. The laparoscopic box trainer exercises are presented in Fig. 1. With regard to hysteroscopic simulators, vegetable models are available like pumpkins and red peppers [16]. Furthermore, chicken meat simulates an endometrium in a water-filled box and a porcine bladder simulates a uterus. A selection of hysteroscopic exercises is presented in Fig. 2. Basic hysteroscopic skills such as camera holding, instrument handling, safe use of energy sources and distention medium are trained. Besides, some procedures like diagnostic hysteroscopy, endometrium resection and resection of polyps or myomas are simulated.

Prior to the start of hands-on training, the exercises are introduced and explained with the aid of audiovisual demonstration. Afterwards, the participants go through a rotation of simulators. The surgical performance is assessed by calculating a score that rewards precision and speed. In the validated exercises, the calculated individual scores are

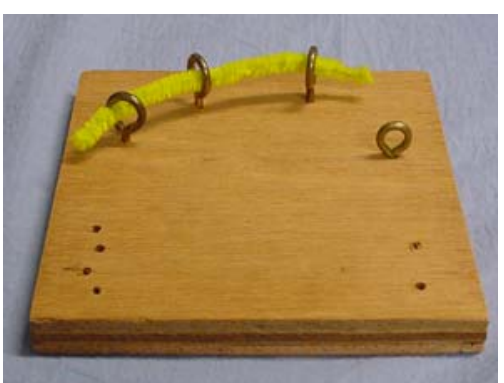

1. Pipe cleaner

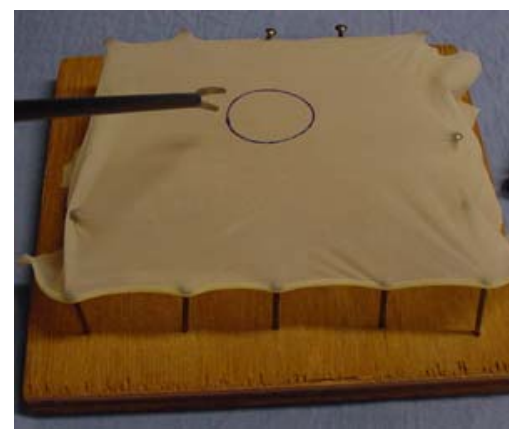

4. Cutting circle

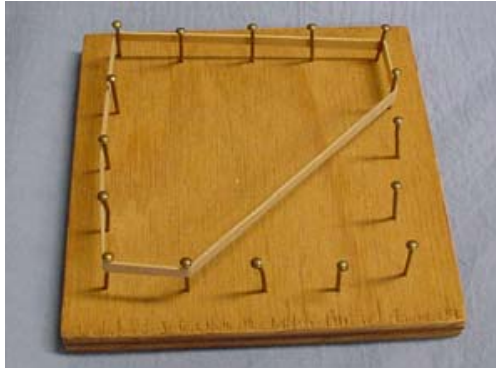

2. Rubber band

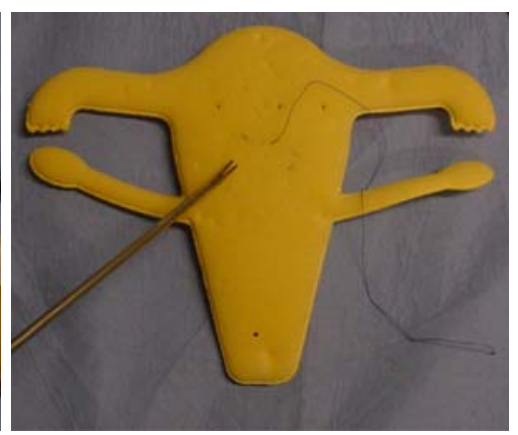

5. Intra-corporeal knot tying

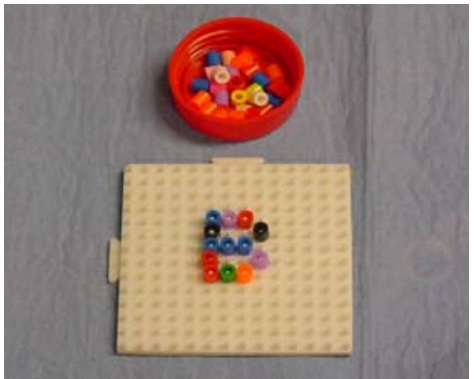

3. Beads

Fig. 1 Laparoscopic training exercises 


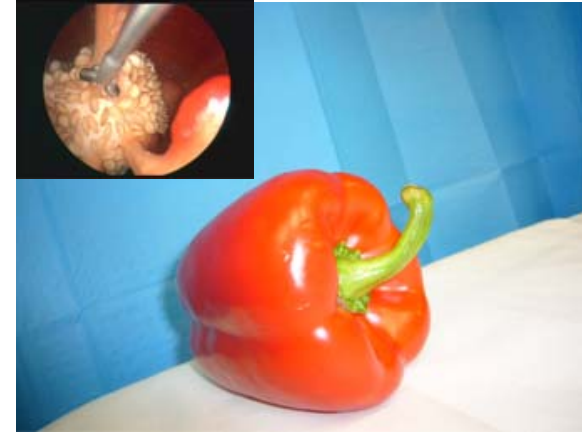

1. Red pepper

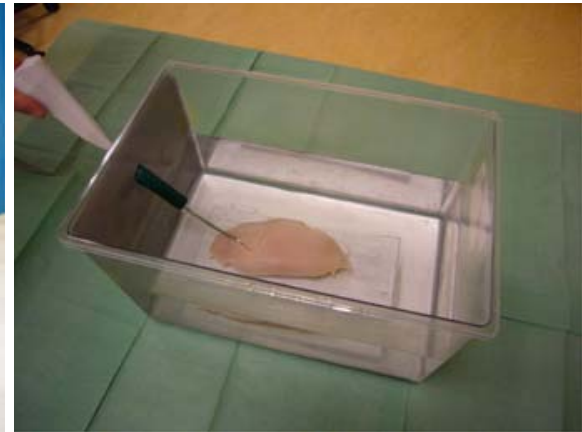

2. Chicken meat in a water filled box

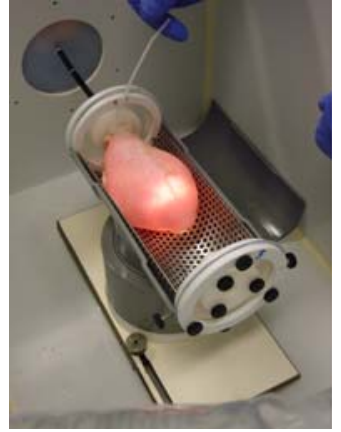

3. Porcine bladder

Fig. 2 Hysteroscopic training exercises

compared to a previously established performance standard [15]. Training on the laparoscopic and hysteroscopic simulators is intensively supervised by experts in MIS. Regarding the number of participants attending the course, which varies from 32 to 36 , each simulator is used by two or three residents and is supervised by one supervising expert.

In addition to the mandatory Cobra-alpha course which is mainly focused on basic skills, residents can apply to two advanced courses in MIS, a laparoscopy course and a hysteroscopy course. These courses can be attended on a voluntary basis. The advanced courses are more procedure orientated than the Cobra-alpha course. In spite of using simulators, life surgery is used for teaching purposes. Procedure-specific courses can further enhance skills and knowledge, like a sacrocolpopexy course and a course regarding laparoscopic adnex surgery. Besides, a variety of (inter)national congresses focuses on MIS are organized.

The mandatory Cobra-alpha course, advanced MIS courses and congresses form the training structure in the Dutch residency curriculum, combined with simulator training in the teaching hospitals during clinical rotation.

\section{Discussion}

The Dutch obstetrics and gynecology residency curriculum has a clear structure regarding the training of MIS skills. A mandatory basic surgical skills course is established for

Table 1 Global rating scale for level of competence

\begin{tabular}{ll}
\hline Level & Definition \\
\hline 1 & Has theoretical knowledge \\
2 & Is able to perform under strict supervision \\
3 & Is able to perform under limited supervision \\
4 & Is able to perform without supervision \\
5 & Is able to supervise and educate others \\
\hline
\end{tabular}

Levels according to NVOG-HOOG, 2005 residency training which is nationwide accepted and has a broad Dutch faculty. Intentionally, the course has to be attended during PGY 1 or PGY 2. Additionally, residents may attend advanced courses and congresses focusing on laparoscopy and hysteroscopy. This structure enhances the implementation of basic MIS skills training into the residency curriculum.

Basic MIS skills can be trained on simulators. Simulators have shown great potential for training and objectively assessing laparoscopic skills [17, 18]. The skills acquired are transferable to real operative procedures [1921] and skills training is shown to decrease patient complications [22]. For every resident, there is a learning curve to achieve proficiency in performing MIS. Presumably, acquiring basic MIS skills by simulator training leads to progression along the first part of this learning curve resulting in better prepared residents for the actual surgery. After achievement of the basic skills, more attention can be paid to the specific procedure during surgery on real patients. With the growing evidence of valuable aspects of

Table 2 Target numbers of MIS procedures required for certification

\begin{tabular}{lll}
\hline Procedure & $\begin{array}{l}\text { Target } \\
\text { number } \\
\text { (total) }\end{array}$ & $\begin{array}{l}\text { Target number } \\
\text { performed on } \\
\text { competence level 4 }\end{array}$ \\
\hline
\end{tabular}

\begin{tabular}{lll}
\hline $\begin{array}{l}\text { Laparoscopic surgery } \\
\text { Diagnostic laparoscopy/ } \\
\quad \text { sterilization }\end{array}$ & 50 & 10 \\
$\quad \begin{array}{l}\text { Minor adhesiolysis } \\
\text { Salpingectomy/ }\end{array}$ & 10 & not applicable \\
$\quad$ salpingotomy (inclusive EP) & 20 & 5 \\
$\quad$ Cystectomy & 10 & not applicable \\
$\begin{array}{l}\text { Hysteroscopy } \\
\text { Diagnostic hysteroscopy }\end{array}$ & 40 & 10 \\
$\quad$ Resection polyps & 10 & 5 \\
$\quad$ Resection myomas type 0-I & 10 & not applicable \\
Resection myomas type II & 10 & not applicable
\end{tabular}

EP Ectopic pregnancy, level 4 able to perform without supervision, target numbers according to NVOG-HOOG, 2005 
MIS simulator training, we feel there is no excuse for depriving residents of this training.

The nationwide basic surgical skills course provides an introduction in simulator training for acquiring MIS skills. However, distributed practice is superior above massed practice, which is provided during a two-day course, for actually achieving these skills $[23,24]$. Consequently, MIS skills can only be acquired if residents continue simulator training and evaluation in their own clinic. A first precondition for this continuance of training is the presence of simulator facilities in every cluster of teaching hospitals. A second precondition is that residents really do use these facilities. The first precondition is partially met. All 46 Dutch teaching hospitals are grouped in eight clusters and simulator training is offered in at least one teaching hospital of each cluster. However, the equipment varies widely among these hospitals. The advantage of training on the simulators used during the Cobra-alpha course is that these are easily fabricated and inexpensive. Besides, the exercises for the laparoscopic box trainer have been validated and a performance standard has been established. Regarding the second precondition, unfortunately, only one third of residents actually train on a simulator if training is offered on a voluntary basis [10]. The fact that most residents do not voluntarily train is in contradiction with the residents' opinion that simulator training is an important addition to their residency program [10]. Hence, formal mandatory MIS training is urgently needed in every training hospital, which has to be scheduled in the busy practice of the residency program.

In spite of structured training, proper evaluation of skills contributes to the learning effect [25]. However, the majority of residents' surgical skills are evaluated informally and in a non-standardized fashion. There is a growing need for objective assessment tools. An example of such a tool is the Objective Structures Assessment of Technical Skills (OSATS). This evaluation method consists of a global rating scale and has proven high reliability and construct validity for simulators $[25,26]$.

Regarding surgical competence, the requirements essential for certification in obstetrics and gynecology are clearly defined in the Netherlands. These requirements are set on a total number of each procedure a resident minimally has to perform. Additionally, the number performed on competence level 4 is established. Level 4 is defined "able to perform without supervision" on a 1 to 5 global rating scale (see Table 1) [27]. The target numbers for the laparoscopic and hysteroscopic procedures are expressed in Table 2 [27]. Although numbers of procedures are easily quantifiable, total numbers do not represent the actual competence of a resident due to individual difference in learning curves $[6$, 28]. Assessing a residents surgical skills and comparing these skills to an established performance standard would be more suitable than counting the number of procedures. In this way, the individual training demands can be met. This emphasizes, on one hand, the importance of objective assessment tools for evaluation of surgical skills and to set a performance standard. On the other hand, simulator training can fulfill the individual training demands, as a source of unlimited training while the training possibilities on real patients in the OR are scarcer. Ultimately, every resident should be able to achieve the predetermined level of skills at the end of residency.

Although some adaptations have to be made to incorporate continued training and evaluation in daily practice, a uniform introduction to MIS training on simulators is guaranteed for every resident in the Netherlands by a mandatory basic skills course, while advanced courses and congresses provide possibilities for enhanced education. Hopefully, this will facilitate and accelerate the implementation of MIS techniques in the gynecological surgical palette.

Open Access This article is distributed under the terms of the Creative Commons Attribution Noncommercial License which permits any noncommercial use, distribution, and reproduction in any medium, provided the original author(s) and source are credited.

\section{References}

1. Darzi A, Mackay S (2002) Recent advances in minimal access surgery. BMJ 324:31-34

2. Gallagher AG, McClure N, McGuigan J, Ritchie K, Sheehy NP (1998) An ergonomic analysis of the fulcrum effect in the acquisition of endoscopic skills. Endoscopy 30:617-620

3. Munz Y, Kumar BD, Moorthy K, Bann S, Darzi A (2004) Laparoscopic virtual reality and box trainers: is one superior to the other? Surg Endosc 18:485-494

4. Blanchard MH, Amini SB, Frank TM (2004) Impact of work hour restrictions on resident case experience in an obstetrics and gynecology residency program. Am J Obstet Gynecol 191:1746-1751

5. Brolmann HA, Vervest HA, Heineman MJ (2001) Declining trend in major gynaecological surgery in The Netherlands during 19911998. Is there an impact on surgical skills and innovative ability? BJOG 108:743-748

6. Feldman LS, Sherman V, Fried GM (2004) Using simulators to assess laparoscopic competence: ready for widespread use? Surgery 135:28-42

7. Loh FH, Hameed N, Ng SC (2002) The impact of minimal access surgery on gynaecological surgery in a university gynaecological unit over a 10-year period from 1991 to 2000. Singap Med J 43:177-181

8. Navez B, Penninckx F (1999) Laparoscopic training: results of a Belgian survey in trainees. Belgian Group for Endoscopic Surgery (BGES). Acta Chir Belg 99:53-58

9. Nussbaum MS (2002) Surgical endoscopy training is integral to general surgery residency and should be integrated into residency and fellowships abandoned. Semin Laparosc Surg 9:212-215

10. Kolkman W, Wolterbeek R, Jansen FW (2005) Gynecological laparoscopy in residency training program: Dutch perspectives. Surg Endosc 19:1498-1502 
11. Kolkman W, Wolterbeek R, Jansen FW (2006) Implementation of advanced laparoscopy into daily gynecologic practice: difficulties and solutions. J Minim Invasive Gynecol 13:4-9

12. Shay BF, Thomas R, Monga M (2002) Urology practice patterns after residency training in laparoscopy. J Endourol 16:251-256

13. Jansen FW, Trimbos-Kemper GCM (2006) Laparoscopy, the basics. Laurier, Noordwijk

14. Trimbos JB (2007) Basics of Surgery, tools, techniques, attitude and expertise. Elsevier, Amsterdam

15. Kolkman W, van de Put MAJ, Jansen FW (2008). Laparoscopic simulator: construct validity and performance standard. Gynecol Surg; in press

16. Kingston A, Abbott J, Lenart M, Vancaillie T (2004) Hysteroscopic training: the butternut pumpkin model. J Am Assoc Gynecol Laparosc 11:256-261

17. Lentz GM, Mandel LS, Lee D, Gardella C, Melville J, Goff BA (2001) Testing surgical skills of obstetric and gynecologic residents in a bench laboratory setting: validity and reliability. Am J Obstet Gynecol 184:1462-1468

18. Scott DJ, Young WN, Tesfay ST, Frawley WH, Rege RV, Jones DB (2001) Laparoscopic skills training. Am J Surg 182:137-142

19. Anastakis DJ, Regehr G, Reznick RK, Cusimano M, Murnaghan J, Brown M, Hutchison C (1999) Assessment of technical skills transfer from the bench training model to the human model. Am $\mathrm{J}$ Surg 177:167-170

20. Hyltander A, Liljegren E, Rhodin PH, Lonroth H (2002) The transfer of basic skills learned in a laparoscopic simulator to the operating room. Surg Endosc 16:1324-1328
21. Seymour NE, Gallagher AG, Roman SA, O’Brien MK, Bansal VK, Andersen DK, Satava RM (2002) Virtual reality training improves operating room performance: results of a randomized, double-blinded study. Ann Surg 236:458-463

22. Cadeddu JA, Wolfe JS Jr., Nakada S, Chen R, Shalhav A, Bishoff JT, Hamilton B, Schulam PG, Dunn M, Hoenig D, Fabrizio M, Hedican S, Averch TD (2001) Complications of laparoscopic procedures after concentrated training in urological laparoscopy. J Urol 166:2109-2111

23. Moulton CA, Dubrowski A, MacRae H, Graham B, Grober E, Reznick R (2006) Teaching surgical skills: what kind of practice makes perfect?: a randomized, controlled trial. Ann Surg 244:400 409

24. Verdaasdonk EG, Stassen LP, van Wijk RP, Dankelman J (2007) The influence of different training schedules on the learning of psychomotor skills for endoscopic surgery. Surg Endosc 21:214-219

25. Reznick R, Regehr G, MacRae H, Martin J, McCulloch W (1997) Testing technical skill via an innovative "bench station" examination. Am J Surg 173:226-230

26. Goff BA, Nielsen PE, Lentz GM, Chow GE, Chalmers RW, Fenner D, Mandel LS (2002) Surgical skills assessment: a blinded examination of obstetrics and gynecology residents. Am J Obstet Gynecol 186:613-617

27. http://www.medischevervolgopleidingen.nl//content/documenten/ specialisme/gynaecologie/nvog_hoog.pdf

28. Park A, Witzke D, Donnelly M (2002) Ongoing deficits in resident training for minimally invasive surgery. J Gastrointest Surg 6:501-507 